[This is an electronic version of a paper published in Proceedings of the Aristotelian Society 108 (2008), 177-196. @ 2008 The Aristotelian Society. Subscribers can download the paper from Wiley InterScience here: http://www3.interscience.wiley.com/journal/120776189/abstract.]

\title{
TRUTHMAKERS AND THE GROUNDEDNESS OF TRUTH
}

\author{
David Liggins
}

Abstract. Truthmaker theorists claim that for every truth, there is something in virtue of which it is true-or, more cautiously, that for every truth in some specified class of truths, there is something in virtue of which it is true. I argue that it is hard to see how the thought that truth is grounded in reality lends any support to truthmaker theory.

I.

Truth is grounded in reality-or so it is appealing to think. Truthmaker theory attempts to articulate this idea precisely and put it to philosophical use. Truthmaker theorists claim that for every truth, there is something in virtue of which it is true-or, more cautiously, that for every truth in some specified class of truths, there is something in virtue of which it is true. These principles yield the conclusion that the world contains entities whose existence guarantees the truth of predications. They also provide arguments against phenomenalism, Ryleanism about dispositions, Rylean behaviourism, operationalism, presentism, and other philosophical theories. In the language of Sider $(2001, \S 2.3)$, truthmaker theory offers a way of 'catching cheaters'.

In this paper, I argue that it is hard to see how the thought that truth is grounded in reality lends any support to truthmaker theory. I begin by summarizing the truthmaker movement in a little more detail (§II). I then discuss an argument put forward by Helen Beebee and Julian Dodd, which aims to show that truthmaker theory could never be justified by the groundedness of truth, on pain of losing its cheater-catching power. I show that this argument fails (§III).

The rest of the paper is less friendly to truthmaker theory. In $\S I V, I$ argue that the groundedness of truth in reality lends it no obvious support. Gonzalo Rodriguez-Pereyra has recently offered an argument for truthmaker theory based on the groundedness of truth; I show that his argument is inconclusive $(\S \mathrm{V})$. In the light of this discussion, it appears that truthmaker theory lacks a decent motivation; I suggest that truthmaker theorists should spend more of their time explaining why we should believe their theories.

I close with a discussion of the principle that truth supervenes on what there is and how it is - a natural line of retreat for truthmaker theorists. I point out that this diluted form of truthmaker theory also lacks a justification (§VI).

II.

Let me begin with a representative quotation from the doyen of truthmaker theorists:

My hope is that philosophers of realist inclinations will immediately be attracted to the idea that a truth, any truth, should depend for its truth on something 'outside' it, in virtue of which it is true. (Armstrong 2004, p. 7) 
(Compare Armstrong 1997, p. 128; Bigelow 1988, p. 123.) 'Realism' and its cognates are shockingly overworked philosophical terms, so it is worth getting slightly clearer on what Armstrong means by 'realist' here. In Armstrong's sense, realism is a wide-ranging and very plausible thesis, the sort of thing that nearly everyone believes. When philosophers (such as Putnam and Rorty) seem to reject it, they are met with howls of outrage. The thesis can be summed up as follows: truth is grounded in reality; how the world is determines what is true; what is true does not determine how the world is. I acknowledge that this formulation is very fuzzy, but it is sharp enough for present purposes. I'll call this commonsense realism (for want of a better term). I take it that Rodriguez-Pereyra (2005, p. 21) is appealing to the same thought when he claims 'truth is grounded' and glosses this in the words: 'Truth is determined by reality'. Commonsense realism is a modest doctrine: it is compatible with the idealist claim that everything is mental. Armstrong's idea is that commonsense realists ought to embrace:

Virtue

For every truth, there is something in virtue of which it is true.

Suppose that $<0$ is $F>$ is a true inessential predication: $o$ is $F$, but $o$ could have existed without being $F$. In virtue of what is it true that $o$ is $F$ ? According to truthmaker theorists, it is not true in virtue of $o$, since it is possible for $o$ to exist without $\langle 0$ is $F>$ being true: to ground that truth, we need an entity whose existence guarantees that it is true. 'If it is said that [a candidate truthmaker] could have failed to make the truth true, then we would surely think that the alleged truthmaker was insufficient by itself and requires to be supplemented in some way' (Armstrong 1997, p. 116; see also Rodriguez-Pereyra 2005, §6; 2006a, pp. 961-2). Truthmaker theorists, then, think that truthmaking involves necessitation:

Necessitarianism

If a proposition $P$ is true in virtue of an entity $o$, then the existence of $o$ entails that $P$ is true.

(By 'the existence of $o^{\prime}$ I just mean '<o exists $>$ '.)

A further piece of terminology is helpful here. Let us call $o$ a truthmaker for a truth $P$ just in case $P$ is true in virtue of $o$. Then Virtue says that every truth has a truthmaker, and Necessitarianism says that a truthmaker for $P$ must entail $P^{\prime}$ s truth.

Combined with Virtue, Necessitarianism yields the following principle, which I'll refer to as 'Maximalism':

For every truth $P$, there is some entity $o$ such that the existence of $o$ entails that $P$ is true.

Maximalists cannot say that the property of Fness is truthmaker for the truth $\langle 0$ is $F>$, for Fness could have existed without $o$ having it. Maximalists are required to believe that there is some entity whose existence guarantees both that $o$ exists and that $<_{0}$ is $F>$ is true. There is room to debate what occupies this theoretical role: candidates include states of affairs (Armstrong 1997), tropes (Mulligan, Simons, and Smith 1984), and conjunctions of resemblance facts (Rodriguez-Pereyra 2002). Whatever the outcome of this debate, the existence of entities guaranteeing the truth of inessential predications is a substantial metaphysical conclusion. 
Moreover, Maximalism provides a way of arguing against philosophical theories: show that they postulate a truth without a truthmaker. Armstrong (1989a, pp. 8-11) credits C.B. Martin with a number of arguments of this sort, targeted at Ryleanism about dispositions, Rylean behaviourism, phenomenalism, and operationalism. Let me sketch out these arguments.

Ryleanism about dispositions denies that attributions of dispositions should be read as assigning properties such as fragility to objects: there are no such properties. Instead, these claims should be read as counterfactuals (or conjunctions of counterfactuals). For instance, perhaps 'The vase is fragile' expresses <If the vase were struck, it would shatter $>.{ }^{1}$ Maximalism challenges this view of dispositions by demanding truthmakers for the counterfactuals used to analyze truths like 'The vase is fragile'. And it is very difficult to see how the Rylean could successfully meet this demand. The most obvious candidates are certain states of affairs (or tropes or whatever guarantees the truth of inessential predications) involving properties such as fragility. But positing such properties would be to abandon the position. Still, there may be a way for Ryleans to reply: posit the state of affairs the world's being such that if the vase were struck, it would shatter. But such moves may be independently problematic; there is something fishy about the property of being such that if the vase were struck, it would shatter (see Sider 2001, pp. 40-41 for a diagnosis). The argument refutes all versions of the position which claim that the counterfactuals are ungrounded, and challenges proponents of the remaining versions to postulate acceptable grounds for them - a challenge that looks hard to meet. Rylean behaviourism asserts that apparent ascriptions of mental properties really attribute dispositions to behave, with dispositions given the treatment I have just set out. The truthmaker argument against Rylean behaviourism is a special case of the argument just given: what serves as truthmaker for these counterfactuals? (See Parsons 1999, pp. 326-7 for commentary.)

According to phenomenalism, claims apparently about physical objects should instead be interpreted as conjunctions of counterfactuals about experiences. Thus the phenomenalist maintains that it is a mistake to add physical objects to our ontology. (Parallel: 'Claims about the average family do not refer to a particular family but are disguised generalizations over all families. It would be confused to add such a thing as the average family to our ontology.') Maximalists challenge phenomenalism by demanding truthmakers for the counterfactuals used to analyze true claims about physical objects. How could a phenomenalist successfully meet this demand? The obvious candidates for truthmakers are property-instances involving physical objects; but to posit physical objects is to give up phenomenalism. This argument is not intended to refute every form of phenomenalism (as Armstrong 2004, p. 2 makes clear): for instance, the phenomenalist can provide a truthmaker for any counterfactual $<$ If $p$, then $q>$ by positing the state of affairs the world's being such that if it were the case that $\mathrm{p}$ then it would be the case that q. But again, there seems something fishy about the properties invoked. Operationalism, which says that claims apparently about physical quantities should be interpreted as conjunctions of counterfactuals about measuring instruments, receives an attack of the same form. As before, Maximalism rules out versions of phenomenalism and operationalism which claim that the counterfactuals are ungrounded, and challenges proponents of the remaining theories to postulate acceptable grounds for them. (Further applications of truthmaker principles are suggested in Lewis 1999, p. 207 and Lewis 2001, p. 614.)

${ }^{1}$ Daly (2002, pp. 104-105) argues that this was not in fact Ryle's view. 
A more recent application of Maximalism sets it against presentism, the thesis that only present things exist. The Maximalist challenges the presentist to provide truthmakers for truths such as $<$ Harold fought at the Battle of Hastings $>$, which appear to have non-present entities as their subject matter. One move is to posit states of affairs such as the world's presently being $a$ world in which Harold fought the Battle of Hastings (see Bigelow 1996). If there are independent reasons to reject such moves, Maximalism can be used to refute presentism.

It is notoriously difficult to find plausible truthmakers for negative existential truths, such $<$ There are no unicorns $>$. $^{2}$ Much of the recent work on truthmaker theory addresses this question. Armstrong's response to the problem is to posit such things as totality facts. These are the states of affairs that a certain sum contains all the Fs. For instance, let A be the mereological sum of all the animals; then the existence of the state of affairs $A$ 's containing all the animals that there are guarantees it's true that there are no unicorns (Armstrong 2004, pp. 75-6). Other truthmaker theorists add absences to their ontology, and claim that the absence of unicorns makes it true that there are no unicorns (Martin 1996, Kukso 2006). Many truthmaker theorists regard these strategies with distaste and respond to the problem of negative existential truths by restricting the scope of their theory. Whilst retaining Necessitarianism, they abandon Maximalism, claiming instead that some truths lack truthmakers (e.g. Simons 2005). ${ }^{3}$ The focus of discussion then becomes: which truths require truthmakers? Do conjunctions, for instance? Do modal truths? (Recent work on this includes Armstrong 2004, pp. 5-7, Simons 2005, p. 254, Mumford 2005, pp. 268-9, Cameron (forthcoming $b$ ), and Cameron (forthcoming c).)

Truthmaker theorists then search for truthmakers for those truths they regard as needing them (see for instance, Armstrong 2004 on general truths, modal truths, mathematical truths, and more; and Cameron (forthcoming $c$ ) on modal truths).

The principles governing truthmaking are another popular avenue of research for truthmaker theorists. Should we, for instance, accept the entailment principle:

If $o$ is a truthmaker for $P$, and $P$ entails $Q$, then $o$ is a truthmaker for $Q$

(see Restall 1996, Rodriguez-Pereyra 2006a, López de Sa (forthcoming))? Should we be tempted by the disjunction thesis:

If $o$ is a truthmaker for $\langle p$ or $q>$, then either $o$ is a truthmaker for $\langle p>$ or $o$ is a truthmaker for $\langle q>$

(see Read 2000, Rodriguez-Pereyra 2006a, López de Sa (forthcoming))?4

${ }^{2}$ It is often said that it is hard to provide truthmakers for 'negative truths'. But, as Parsons (2006, pp. 591-2) points out, this phrase is obscure.

3 Other responses to the problem of negative existentials include Beall 2000, Cheyne and Pigden 2006, Mumford 2007, and Cameron (forthcoming b). Dodd 2007 argues that there is no satisfactory solution, rejecting truthmaker theory for this reason (see also Parsons 2006).

4 A helpful survey of the literature on truthmakers is provided by Rodriguez-Pereyra $2006 b$. 
III.

Previous authors have already remarked that truthmaker theorists typically provide very little motivation for their views (Dodd 2002, Merricks 2007). For instance, Armstrong (1989b, p. 89) describes his own Maximalist version of truthmaker theory as 'fairly obvious once attention is drawn to it' and admits that he has no argument for it. Sometimes truthmaker theorists offer what look like arguments for truthmaker theory which on inspection turn out to be fallacious, suggesting that they are best understood as intuition-joggers (e.g. Bigelow 1988, p. 126, Armstrong 1997, p. 116, and Armstrong 2004, pp. 6-7; for criticism, see Dodd 2002, pp. 79-80, Parsons 1999, pp. 330-333, and Merricks 2007, pp. 8-9 respectively). If truthmaker theory is to help us make progress in philosophy, this cannot be regarded as satisfactory. Until we are given a reason to believe in truthmaker theory, arguments that appeal to truthmaker principles can be dismissed with perfect ease.

Some truthmaker theorists may be happy with this. They do not think that truthmaker principles can be used as philosophical tools. Such versions of truthmaker theory are not my concern here; I want to see whether truthmaker theory can deliver the results I laid out above. I will therefore examine whether truthmaker theory can be respectably motivated. As we have seen, Armstrong suggests that 'philosophers of realist inclinations' will be 'attracted to' Virtue. As far as I know, this is the only source of support that has been claimed for truthmaker theory. Before discussing whether commonsense realism provides any motivation for truthmaker theory, I will consider an argument put forward by Beebee and Dodd, who claim that any attempt to justify truthmaker theory by appeal to commonsense realism will drain it of its cheater-catching power.

Beebee and Dodd write:

$[\mathrm{H}]$ ow can truthmaker theory ... legitimately be put to use in an argument for realism (about a particular domain) and against anti-realism? If truthmaker theory itself enshrines a commitment to realism, then presumably the appropriate anti-realist reaction to such an argument is simply to deny whatever truthmaker principle is being used as a premise in that argument. If a given truthmaker principle is to pull its weight in arguments against anti-realism, then we had better have reasons, independently of our commitment to realism, for believing that the principle is true. We wonder whether such reasons are to be had. (Beebee and Dodd 2005, p. 16)

This argument is potentially very powerful. If it is correct, then it must be impossible to use the groundedness of truth in reality to argue against phenomenalism, Rylean behaviourism, and the like. I claim that Beebee and Dodd's argument confuses different senses of 'realism' and collapses once these are distinguished. In reply to Beebee and Dodd, I'll show that truthmaker theorists' attack on phenomenalism is not question-begging; then I'll generalize the point.

There is a sense of 'realism' in which phenomenalism is a form of anti-realism about physical objects. This sense of 'realism' can be captured by a formulation on the following lines (based on Miller 2005):

Tables, chairs, books, and so on, exist, and the fact that they exist is (apart from mundane empirical dependencies of the sort sometimes encountered in everyday 
life) independent of anyone's beliefs, linguistic practices, conceptual schemes, and so on.

Call this physical object realism. Phenomenalism doesn't count as a form of physical object realism, since phenomenalists deny that physical objects exist.

The first sentence of the passage from Beebee and Dodd quoted above suggests that appealing to realism is intended to refute every anti-realist view of the domain in question. But this is not what truthmaker theorists have in mind. Consider the following error-theoretic position: although our thought and talk often attempts to refer to physical objects, there are no such things, and so these thoughts and utterances are all untrue. This is clearly not a form of physical object realism, for it denies that physical objects exist. But truthmaker theorists have never claimed that truthmaker theory refutes this view. Moreover, they are wise to avoid that claim. This form of anti-realism about physical objects is compatible with commonsense realism, since it does not entail that there are truths which float free from reality. Appeals to commonsense realism have no chance of refuting it.

With that clarification made, let me agree that it would indeed be question-begging to use physical object realism as a premiss in an argument against phenomenalism. The truthmaker argument against phenomenalism, however, is of a more virtuous type. It makes no appeal to physical object realism; rather, it appeals to commonsense realism. These doctrines are clearly distinct: commonsense realism is a wide-ranging thesis about what determines the truth-values of propositions, whereas physical object realism is a thesis about the existence and mind-independence of physical objects. That said, the argument would still be worrying if physical object realism were a consequence of commonsense realism; but we have just seen that this is not the case.

The same point obtains more generally. The debate about physical objects is just one of a number of number of debates between realism and anti-realism. Each of the doctrines the truthmaker theorists seek to attack (Rylean behaviourism, operationalism, and so on) belongs to one of these debates and counts a version of anti-realism in the relevant sense of 'realism' at issue in that particular debate. But none of their arguments takes any of these local forms of realism as a premiss; moreover, none of these local forms of realism is entailed by commonsense realism, since commonsense realism is compatible with error theory about any domain. Therefore the truthmaker theorists' arguments do not beg the question.

IV.

Does commonsense realism support truthmaker theory? In this section, I argue that it is very difficult to see how.

Commonsense realism has the consequence that it will never be a brute matter that a proposition has a particular truth-value; rather, it will always be explicable by pointing to how the world is (provided we know enough). This is because commonsense realism says that the truth-values of propositions are determined by reality. As Rodriguez-Pereyra says, 'What reality is like ... gives rise to the truth of the proposition and thereby accounts for it' (2005, p. 21, footnote removed). So commonsense realists should embrace:

$\operatorname{Exp}$

For every truth $P$, there is an explanation of why $P$ is true. 
Now there is a reading of Virtue on which it is just another way of articulating Exp. On this reading of Virtue, commonsense realists should endorse it. But this principle is of no obvious use for motivating truthmaker theory.

On what reading then does Virtue support truthmaker theory? Neither of the following readings will help:

V1

For every truth $P$, there is some entity $o$ such that $o$ determines that $P$ is true

V2

For every truth $P$, there is some entity $o$ such that $o$ explains why $P$ is true.

These principles lie some distance away from truthmaker theory. Someone who endorsed V1 could claim that the rose determines whether it's true that the rose is red; they could say that that truth is true in virtue of the rose. But as the rose is only contingently red, this would contradict Necessitarianism. And the same goes for V2.

It therefore appears that truthmaker theorists have in mind not V1 or V2, but:

V3

For every truth $P$, there is some entity $o$ such that $o$ 's existence determines that $P$ is true

or

V4

For every truth $P$, there is some entity $o$ such that $o$ 's existence explains why $P$ is true.

But neither of these principles is a consequence of commonsense realism. Commonsense realists think that truth is determined by reality; but that does not mean that they should think that propositions owe their truth-values simply to what exists. It is more natural to think that there are propositions which owe their truth-values not just to what exists but also to how it is - which properties it has and in what relations it stands (see Dodd 1999, 2002; Robinson 2002, p. 151). Perhaps it is true that the rose is red, not because of the existence of some entity - the rose's redness, say-but because the rose exists and has the property of redness.

Truthmaker theorists evidently find it plausible that the existential explanations are the best ones. Ross Cameron (forthcoming a) sums up 'the whole spirit of truthmaker theory' in the following words: 'the ontological inventory being as it is should not leave the truth-value of any proposition undecided'; and Stephen Read (2000, p. 76) describes truthmaker theory as capturing the 'insight ... that what is true is made so by the existence of something else'. But to the best of my knowledge, only one truthmaker theorist, Gonzalo Rodriguez-Pereyra $(2005, \S 6$ ), has offered an argument for the superiority of these explanations; and that argument has been refuted by Jennifer Hornsby $(2005, \S 2)$.

To sum up: commonsense realism supports Virtue, but only if it is read in a way that lends no clear support to truthmaker theory; and related principles which would support truthmaker theory go beyond commonsense realism. So there is it no obvious reason why 
commonsense realists should be truthmaker theorists. If truthmaker theorists want us to believe their theories on the basis of commonsense realism, they owe us an argument.

V.

Very few truthmaker theorists have offered such an argument; Rodriguez-Pereyra $(2005, \S 7)$ is an exception. I will now set out his argument and show that it is inconclusive. ${ }^{5}$

According to Rodriguez-Pereyra's (2006a, p. 979) preferred version of truthmaker theory:

\section{TMS}

Every synthetic truth has a truthmaker.

Rodriguez-Pereyra argues for TMS on the basis that it provides the best explanation of the following asymmetry. ${ }^{6}$ For many substitutions for ' $p$ ', we have:

(A)

$\langle p\rangle$ is true because $p$;

whereas the following is not the case:

(ConA)

$p$ because $\langle p>$ is true.

For example, <The rose is red $>$ is true because the rose is red; but we cannot explain why the rose is red by pointing to truth of any proposition, not even $<$ The rose is red $>$.

Call this phenomenon the truth asymmetry. I will not stop to determine its scope, except to remark that the usual (paradoxical, indexical) exceptions to ' $\langle p\rangle$ is true iff $p$ ' are exceptions to (A) as well, and that some would regard all analytic propositions, or all necessary propositions, as further exceptions. What matters here is that there are many true instances of (A) where $\langle p\rangle$ is synthetic and the corresponding instance of (ConA) is false.

As Rodriguez-Pereyra (2005, p. 21) notes, the truth asymmetry is a consequence of commonsense realism. Commonsense realism tells us that if $\langle p\rangle$ is true, it is true because of how reality stands; in particular, it is true because reality stands in the way that $\langle p\rangle$ describes it as standing, that is, because $p$. But the converse is not the case, since what is true is determined by how the world is, not vice versa. Thus Rodriguez-Pereyra aims to establish TMS by showing that it best explains a consequence of commonsense realism.

${ }^{5}$ Hornsby $(2005, \S 4)$ and Dodd $(2007, \S \S V I-V I I)$ also criticize Rodriguez-Pereyra's argument. I am sympathetic to the replies to Hornsby and Dodd given in Rodriguez-Pereyra (forthcoming 2008). Soames (forthcoming) offers a rival explanation of the truth asymmetry, and thus in effect offers another reply to Rodriguez-Pereyra's argument; I will not discuss Soames's argument here.

6 Strictly, in his 2005 Rodriguez-Pereyra argues for the claim that 'the members of an important class of synthetic true propositions, including inessential predications' (p. 18) have truthmakers; he allows that some synthetic truths lack truthmakers (p. 20 n. 7). But nothing except for cumbersome qualifications will be lost by treating it as an argument for his 2006 view. 
To explain the truth asymmetry, we need an explanation of why instances of (A) are true which cannot be turned into a parallel explanation of why the corresponding instances of (ConA) are true. Rodriguez-Pereyra makes his case by arguing against several possible strategies for explaining the asymmetry, and then offering his own explanation. For instance, he considers Horwich's (1998) explanation of why instances of (A) are true. Horwich claims that they are true because (in general) $\langle p>$ entails $\langle<p>$ is true $>$. Rodriguez-Pereyra (2005, p. 27) points out that this does not lead to an explanation of the asymmetry, since the converse entailment, from $\langle<p>$ is true $>$ to $\langle p\rangle$, also holds.

Rodriguez-Pereyra's own explanation runs as follows. There is a binary relation - the grounding relation-such that:

TV

For every synthetic proposition $\mathrm{P}, P$ is true iff there is some entity $x$ such that $x$ grounds $P$.

For example, if $<$ The rose is red $>$ is true then there must be some entity that grounds it. Rodriguez-Pereyra claims that the property of truth is the relational property of being grounded by something or other. Add on the claim that $P$ is grounded by $o$ iff $P$ is true in virtue of $o$, and TV becomes TMS.

Rodriguez-Pereyra also claims that the grounding relation is asymmetrical: whenever $o$ grounds $P, P$ does not ground $0 .{ }^{7}$ For instance, suppose that the fact that the rose is red grounds $<$ The rose is red $>$ is; then it will not be the case that $<$ The rose is red $>$ grounds the fact that the rose is red. Only true propositions have grounds. This is the key to Rodriguez-Pereyra's explanation of the truth asymmetry: the truth asymmetry obtains because the grounding relation is asymmetrical. ${ }^{8}$

How exactly are instances of (A) and (ConA) connected to the grounding relation? Rodriguez-Pereyra's article suggests two possible ways. I will now consider these in turn.

The first possibility is that instances of (A) and (ConA) are claims about grounding. Perhaps the word 'because' in them functions as a two-place predicate picking out the grounding relation. If this were true, then the truth asymmetry would flow directly from the asymmetry of the grounding relation. Consider the height asymmetry: in no case where $x$ is taller than $y$ do we also have that $y$ is taller than $x$. If 'is taller than' picks out an asymmetrical relation, then the height asymmetry is accounted for.

However, it is very unlikely that 'because' picks out the grounding relation. Consider the following instance of $(\mathrm{A})$ :

$<$ The rose is red $>$ is true because the rose is red.

\footnotetext{
7 See Rodriguez-Pereyra (2005, p. 22, n. 9) for a slight qualification which can be ignored here.

8 This departs a little from Rodriguez-Pereyra's own statement of the argument, which is in terms of explaining what it is for instances of (A) to be true ('What is it ... for the proposition that the rose is red to be true because the rose is red?' (p. 27)). This way of putting it is strange: why should we expect there to be informative answers to such questions? Hornsby and Dodd read the argument in the same way as I do.
} 
If 'because' were a predicate here, then '<The rose is red $>$ is true' would have to be a singular term referring to $<$ The rose is red $>$, and 'the rose is red' would have to be a singular term referring to some truthmaker for $<$ The rose is red $>$. But neither expression looks like a singular term: it is far more natural to regard both of them as sentences, in which case 'because' is not a predicate but a sentential connective. It should be uncontroversial that ' $<$ The rose is red $>$ is true' and 'The rose is red' sometimes function as sentences; to claim that they do not always do so, but sometimes double as singular terms, would be to postulate additional semantic complexity without independent motivation. To claim that 'because' is sometimes a predicate would be no less ad hoc.

I have been assuming that sentences do not refer, but that assumption is dispensable. Perhaps sentences refer to truth-values, as Frege claimed. All my argument requires is that ' $<$ The rose is red $>$ is true' does not refer to a proposition; and that 'the rose is red' does not refer to a truthmaker for <The rose is red $>$. These claims are plausible; even hardline Fregeans should be happy with them.

Similar remarks apply to the view that ' $<$ The rose is red $>$ ' refers to $<$ The rose is red $>$, 'is true because' picks out the grounding relation, and 'the rose is red' refers to some truthmaker for $<$ The rose is red $>$. We have no independent reason to accept either the second or the third of these claims.

So much for the first way in which instances of (A) and (ConA) might be connected to the grounding relation: by expressing claims about grounding. I now turn to consider a second way suggested by Rodriguez-Pereyra. The idea is that, although these sentences do not express claims about grounding, certain grounding relations must obtain in order for them to be true.

An analogy with sentences stating causal explanations is suggestive here. Consider, for example, the sentence 'The bottle smashed because it was dropped'. Like instances of (A) and (ConA), this is not relational in form: it is composed of two shorter sentences linked by the sentential connective 'because'. (I will assume this for the sake of argument.) But perhaps in order for it to be true, there must be two events-namely, the smashing of the bottle and the dropping of the bottle-and it must be the case that the latter bears the causal relation to the former. More generally, perhaps the truth of each causal explanation of the form ' $p$ because $q$ ' requires the existence of two events (appropriately related to ' $p$ ' and ' $q$ ' respectively) and requires that the latter bears the causal relation to the former.

Things might run parallel with the sentences involved in the truth asymmetry. Perhaps, in order for '<The rose is red $>$ is true because the rose is red' to be true, there must be such things as $<$ The rose is red $>$ and a truthmaker for that proposition, and the latter must ground the former. Although the sentence does not say that these two things are so related, perhaps they must be in order for the sentence to be true. More generally, perhaps the relevant instances of the following schemata are all true:

(GA)

If $\langle p\rangle$ is true because $p$, then there is some entity $x$ such that $x$ grounds $\langle p\rangle$.

(GConA)

If $p$ because $\langle p>$ is true, then there is some entity $x$ such that $\langle p>$ grounds $x$. 
Just as causal explanations are underpinned by causal relations, it may be that the sorts of explanations offered by instances of (A) and (ConA) are underpinned by grounding relations. If that were true, then the truth asymmetry would follow from the asymmetry of the grounding relation.

The question now is this: why should we believe instances of (GA) and (GConA)?

In answer to this question, Rodriguez-Pereyra (2005, p. 28) cites with approval David-Hillel Ruben's thesis (1990, p. 210) that explanations are always underpinned by 'determinative relations' between entities. The idea is this: whenever we have a true sentence of the form ' $p$ because $q$ ', there are entities $x$ and $y$, appropriately related to ' $p$ ' and ' $q$ ' respectively, such that $y$ bears some relevant 'determinative relation' to $x$. Ruben counts causation and identity as 'determinative relations', and is willing to allow that there may be more. Rodriguez-Pereyra suggests, in effect, that grounding should be added to the list.

My response to this argument is to ask for a reason to believe Ruben's thesis. Provided we believe in the existence of events, facts, or some other suitable entities, then it will be plausible that causal explanations are underpinned by relations between these entities. But why extend the idea to cover all non-causal explanations too? Ruben provides no argument for his thesis. He does show that some non-causal explanations fit into his pattern, but that falls short of establishing that they all do. Moreover, there seem to be plenty which do not obviously conform to Ruben's thesis. Take, to begin with:

There are no unicorns in Knutsford because there are no unicorns at all.

$<$ Harold fought at the Battle of Hastings $>$ is true because Harold fought at the Battle of Hastings

Further examples can be generated by taking true sentences expressing synthetic truths which do not obviously have a truthmaker, and substituting then in explans or explanandum position. It is not clear that there are entities correlated with these truths; that is what is at issue. So it is not clear that Ruben's thesis covers explanations involving them.

The topic of non-causal explanation is poorly understood at present; more work in this area is needed. It is not yet clear whether Ruben's thesis is true-so it is not yet clear whether it can be deployed in the service of truthmaker theory. If we are to believe Ruben's thesis, then we need an argument; but no such argument has yet been produced. Rodriguez-Pereyra's argument is therefore inconclusive.

VI.

We have seen that commonsense realism provides no clear support for truthmaker theory. In the absence of any compelling arguments for truthmaker theory, I conclude that it lacks a proper motivation. ${ }^{9}$ This means that truthmaker principles are useless for catching cheaters or showing there are entities guaranteeing the truth of inessential predications: these arguments can be dismissed by rejecting the truthmaker principles they employ.

9 Further concerns about motivating truthmaker theory are expressed in Williamson 1999, Dodd 2002, Beebee and Dodd 2005, and Daly 2005. 
I conclude from this that truthmaker theorists are using their resources unwisely. The bulk of their recent work presupposes that many truths have truthmakers. But this is a presupposition to which truthmaker theorists are not entitled. Before they discuss the problem of negative existentials, or attempt to determine general principles of truthmaking, enthusiasts for truthmakers ought to explain why any truth has a truthmaker. The foundations should be in place before the rest of the house is built. Truthmaker theorists have several options. They may supplement Rodriguez-Pereyra's argument, to try to make it into a conclusive justification for truthmaker theory; or they may look for another path from commonsense realism to truthmaker theory; or they may offer a justification with a different starting-point.

Instead of arguing for truthmaker theory, truthmaker theorists might prefer to abandon it. One line of retreat is to embrace the thesis that truth supervenes on what exists and how it is-more formally:

Sup

For any proposition $P$ and any worlds $W$ and $V$, if $P$ is true in $W$ but not in $V$, then either something exists in one of the worlds but not in the other, or else some $n$-tuple of things stands in some relation in one of the worlds but not in the other. ${ }^{10}$

Here, properties are counted as monadic relations.

Sup is endorsed by Lewis $(2001,2003)$ and Dodd (2002). Lewis (2001) points out that if Sup is true, we can use it to catch cheaters. Let me spell this out a little.

Phenomenalists say that there are no physical objects; by their lights, claims apparently about them should be interpreted as conjunctions of counterfactuals about experiences. Consider, for instance, 'The cup is round'. Let $\mathrm{C}$ be the conjunction of counterfactuals into which the phenomenalist analyzes this claim. Since the cup is round, $\mathrm{C}$ will be true. According to Sup, for $\mathrm{C}$ to be false, there would have to be some difference in what there is or how it is. The obvious way to meet this requirement is to cite the cup and how it is; if it didn't exist, or weren't round, then $C$ would be false. But because phenomenalists reject the existence of the cup, they cannot meet Sup in this way. It is very hard to see how they could meet it in an acceptable fashion. As before, we have a refutation of certain forms of phenomenalism and a challenge to others.

Presentists, who claim that only present things exist, have a hard time squaring their view with Sup. $<$ Harold fought at the Battle of Hastings $>$ is true, but could have been false. For this proposition to be false, there must be some difference in what there is or how it is (or both); so Sup says. But what could this difference be? (For criticism of presentist attempts to accommodate Sup, see Sanson and Caplan (forthcoming).)

10 This is Lewis's (TM=) (Lewis 2001, p. 612), with 'fundamental relation' replaced by 'relation'. For a refinement (which need not detain us here), see Keller (2004, p. 85 n. 7).

A less drastic retreat is to embrace the thesis that truth supervenes on what exists:

For any proposition $P$ and any worlds $W$ and $V$, if $P$ is true in $W$ but not in $V$, then either something exists in $V$ but not in $W$ or else something exists in $W$ but not in $V$.

(This is Lewis's (TM-) (Lewis 2001, p. 610).) Dodd 2002 provides a sceptical discussion of this move. 
Sup offers arguments against other cheaters too. For instance, it is easy to see how to argue against Rylean behavourism, Ryleanism about dispositions, and operationalism in a similar vein. Prima facie, any cheater-catching argument the truthmaker theorist offers can be mimicked by invoking the supervenience of truth on what there is and how it is.

Sup provides no argument for the existence of entities to guarantee the truth of inessential predications. Consider the truth $<$ The rose is red $>$. We can meet Sup by saying that in every world where this is false, either the rose doesn't exist, or it doesn't instantiate the property of redness. Sup does not require us to postulate anything like the rose's redness. Still, Sup promises to do some of the work that truthmaker theory offered to accomplish.

At present, though, Sup is useless for catching cheaters, because it has never been properly argued for. Cheaters can evade capture simply by refusing to accept Sup.

Lewis (2001) arrives at Sup by watering down truthmaker theory to avoid objections. But since there is no decent motivation for truthmaker theory in the first place, this ought not to persuade us of Sup. At present, Sup stands in need of justification. The same goes for truthmaker theory. ${ }^{11}$

Philosophy

School of Social Sciences

University of Manchester

Oxford Road

Manchester

M13 9PL

UK

david.liggins@manchester.ac.uk

\section{References}

Armstrong, D.M 1989a: 'C.B. Martin, Counterfactuals, Causality, and Conditionals' . In John Heil (ed.) Cause, Mind, and Reality (Dordrecht: Kluwer), pp. 7-15.

- 1989: Universals: An Opinionated Introduction (Boulder: Westview Press).

- 1997: A World of States of Affairs (Cambridge: Cambridge University Press).

- 2004: Truth and Truthmakers (Cambridge: Cambridge University Press).

Beall, J. 2000: 'On Truthmakers for Negative Truths'. Australasian Journal of Philosophy, 78, pp. 264-268.

Beebee, H. and J. Dodd (eds) 2005: Truthmakers: The Contemporary Debate (Oxford: Clarendon Press).

- 2005: 'Introduction'. In Beebee and Dodd (eds) 2005, pp. 1-16.

Bigelow, J. 1988: The Reality of Numbers: A Physicalist's Philosophy of Mathematics (Oxford: Clarendon Press).

-1996: 'Presentism and Properties'. Philosophical Perspectives, 10, pp. 35-52.

11 My thanks to Anna Mahtani, Chris Daly, Gonzalo Rodriguez-Pereyra, Joel Smith, Julian Dodd, Jules Holroyd, Rosanna Keefe, Ross Cameron, and Tom Smith. I would also like to thank the audience at the Aristotelian Society meeting at which this paper was presented, and audiences in Manchester and Geneva. 
Cameron, Ross (forthcoming a): 'Truthmakers, Realism and Ontology'. In R. LePoidevin (ed) Being: Contemporary Developments in Metaphysics (Cambridge: Cambridge University Press).

- (forthcoming $b$ ): 'How to be a Truthmaker Maximalist'. Noûs.

- (forthcoming $c$ ): 'Truthmakers and Modality'. Synthese.

Cheyne, C. and C. Pigden 2006: 'Negative Truths from Positive Facts'. Australasian Journal of Philosophy 84, pp. 249-265.

Daly, C. 2002: 'Properties as Truthmakers'. Logique \& Analyse, 169-170, pp. 95-107.

- 2005: 'So Where's the Explanation?' In Beebee and Dodd (eds) 2005, pp. 85-103.

Dodd, J. 1999: 'Farewell to States of Affairs'. Australasian Journal of Philosophy, 77, pp. 161-173.

- 2002: 'Is Truth Supervenient on Being?' Proceedings of the Aristotelian Society, 102, pp. 69-86.

- 2007: 'Negative Truths and Truthmaker Principles'. Synthese, 156, pp. 383-401.

Hornsby, J. 2005: 'Truth without Truthmaking Entities'. In Beebee and Dodd (eds) 2005, pp. 33-47.

Horwich, P. 1998: Truth, 1st edn. (Oxford: Clarendon Press).

Keller, S. 2004: 'Presentism and Truthmaking'. In Dean W. Zimmerman (ed.) Oxford Studies in Metaphysics, Volume 1 (Oxford: Clarendon Press), pp. 8-104.

Kukso, B. 2006: 'The Reality of Absences'. Australasian Journal of Philosophy, 84, pp. 21-37.

Lewis, D. 1999: Papers in Metaphysics and Epistemology (Cambridge: Cambridge University Press).

- 2001: 'Truthmaking and Difference-Making'. Nô̂s, 35, pp. 602-615.

- 2003: 'Things qua Truthmakers'. In H. Lillehammer and G. Rodriguez-Pereyra (eds) Real Metaphysics: Essays in Honour of D.H. Mellor (London and New York: Routledge), pp. 25-38.

López de Sa, D. (forthcoming): 'Disjunctions, Conjunctions, and their Truthmakers'. Mind. Martin, C.B. 1996: 'How it Is: Entities, Absences and Voids.' Australasian Journal of Philosophy, 74, pp. 57-65.

Merricks, T. 2007: Truth and Ontology (Oxford: Clarendon Press).

Miller, A. 2005: Realism. In Edward N. Zalta (ed.) The Stanford Encyclopedia of Philosophy (Fall 2005 Edition). URL = <http://plato.stanford.edu/archives/fall2005/entries/realism/>.

Mulligan, K., and P. Simons and B. Smith 1984: 'Truth-Makers'. Philosophy and Phenomenological Research, 44, pp. 287-321.

Mumford, S. 2005: 'The True and the False'. Australasian Journal of Philosophy, 83, pp. 263-269.

- 2007: 'Negative Truth and Falsehood'. Proceedings of the Aristotelian Society, 107, pp. 45-71.

Parsons, J. 1999: 'There is no "Truthmaker" Argument against Nominalism'. Australasian Journal of Philosophy, 77, pp. 325-334.

- 2006: 'Negative Truths from Positive Facts?' Australasian Journal of Philosophy, 84, pp. 591-602.

Read, S. 2000: 'Truthmakers and the Disjunction Thesis'. Mind, 109, pp. 67-79.

Restall, G. 1996: 'Truthmakers, Entailment and Necessity'. Australasian Journal of Philosophy, 74, pp. 331-340.

Robinson, D. 2002: 'Identities, Distinctnesses, Truthmakers, and Indiscernibility Principles'. Logique \& Analyse, 169-170, pp. 145-183.

Rodriguez-Pereyra, G. 2002: Resemblance Nominalism: A Solution to the Problem of Universals (Oxford: Clarendon Press). 
- 2005: 'Why Truthmakers'. In Beebee and Dodd (eds) 2005, pp. 17-31.

- 2006a: 'Truthmaking, Entailment, and the Conjunction Thesis'. Mind, 115, pp. 957-981.

- 2006b: 'Truthmakers'. Philosophy Compass, 1/2, pp. 186-200.

- (forthcoming 2008): 'Postscript to "Why Truthmakers"'. In E. J. Lowe and A. Rami (eds) Truth and Truth-Making (Stocksfield: Acumen).

Ruben, D.-H. 1990: Explaining Explanation (London and New York: Routledge).

Sanson, D., and B. Caplan (forthcoming): 'The Way Things Were'. Philosophy and Phenomenological Research.

Soames, S. (forthcoming): 'Truthmakers?'. Philosophical Books.

Sider, T. 2001: Four-Dimensionalism: An Ontology of Persistence and Time (Oxford: Clarendon Press).

Simons, P. 2005: 'Negatives, Numbers, and Necessity: Some Worries about Armstrong's Version of Truthmaking'. Australasian Journal of Philosophy, 83, pp. 253-261.

Williamson, T. 1999: 'Truthmakers and the Converse Barcan Formula'. Dialectica, 53, pp. 253-270. 